\title{
Bulk Glassy GeTe2: a Missing Member of Tetrahedral GeX2 Family and a Precursor for the Next Generation of Phase Change Materials
}

Andrey Tverjanovich, ${ }^{a}$ Maxim Khomenko, ${ }^{b}$ Chris J. Benmore, ${ }^{c}$ Maria Bokova, ${ }^{d}$ Anton Sokolov, ${ }^{b, d}$ Daniele Fontanari, ${ }^{d}$ Mohammad Kassem, ${ }^{d}$ Takeshi Usuki, ${ }^{e}$ and Eugene Bychkov ${ }^{b, d *}$

${ }^{a}$ Institute of Chemistry, St. Petersburg State University, 198504 St. Petersburg, Russia

${ }^{b}$ ILIT RAS - Branch of the FSRC 'Crystallography and Photonics' RAS, 140700 Shatura, Moscow Region, Russia

${ }^{c}$ X-ray Science Division, Advanced Photon Source, Argonne National Laboratory, Argonne, Illinois 60439, United States

${ }^{d}$ Laboratoire de Physico-Chimie de l'Atmosphère, Université du Littoral Côte d'Opale, 59140 Dunkerque, France

$e$ Faculty of Science, Yamagata University, Yamagata 990-8560, Japan

\section{Supporting Information}

Figure S1. DSC traces of selected Ge-Te bulk glasses and the compositional dependence of the glass transition temperature; typical examples of the obtained bulk glassy $\mathrm{GeTe}_{2}$.

Figure S2. (a) Experimental and derived FPMD interference functions $Q\left[S_{\mathrm{X}}(Q)-1\right]$ for glassy $\mathrm{GeTe}_{2}$; (b) partial structure factors $S_{\mathrm{ij}}(Q)$ for Ge-Ge (dark green), Ge-Te (light green) and Te-Te (gray) atomic pairs.

Figure S3. Tetrahedral orientational order parameter $q$ for $\mathrm{GeTe}_{4}$ polyhedra in bulk glassy $\mathrm{GeTe}_{2}$.

Figure S4. (a) Optimized DFT cluster ETH- $\mathrm{Ge}_{2} \mathrm{Te}_{6}$ and (b) derived DFT Raman spectrum.

Figure S5. Size of (a) $\mathrm{Te}_{n}$ and (b) $\mathrm{Ge}_{n}$ oligomers in liquid $\mathrm{GeTe}_{2}$ at $1000 \mathrm{~K}$.

Figure S6. Fraction of Ge-Ge homopolar bonds in glassy, supercooled and liquid $\mathrm{GeTe}_{2}$ as a function of temperature.

Figure S7. Germanium and tellurium mean-square displacements in liquid $\mathrm{GeTe}_{2}$ at (a) $800 \mathrm{~K}$ and (b) $1300 \mathrm{~K}$.

Figure S8. Germanium $D_{\mathrm{Ge}}$ and tellurium $D_{\mathrm{Te}}$ diffusion coefficients in liquid $\mathrm{GeTe}_{2}$.

Table S1. Optimized Geometry Parameters (Ge-Te, Ge-Ge and Te-Te interatomic distances, Te-Ge-Te and Ge-Te-Ge bond angles) of Size-Limited Ge-Te Clusters Used in DFT Modeling of Vibrational Properties 

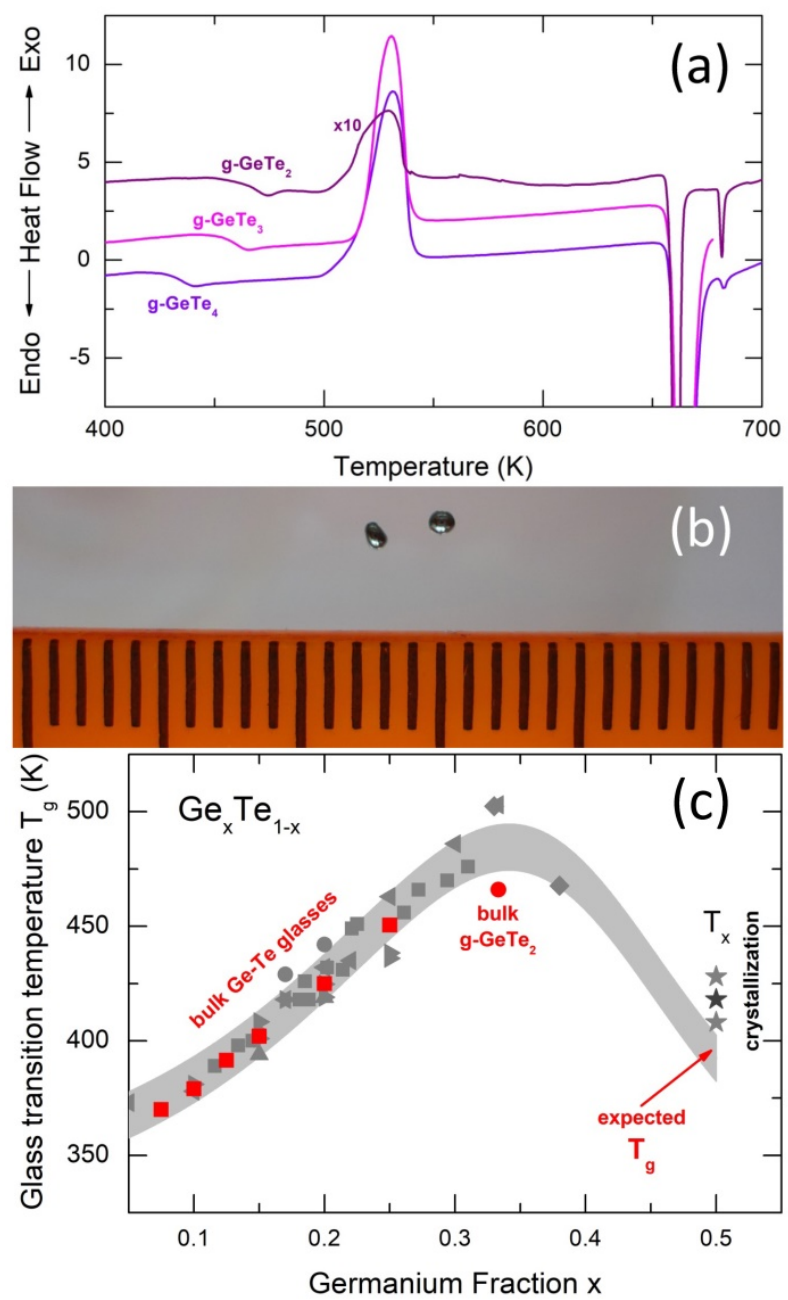

Figure S1. (a) DSC traces of glassy $\mathrm{GeTe}_{2}(x=1 / 3)$, usual $\mathrm{GeTe}_{3}(x=0.25)$ and $\mathrm{GeTe}_{4}(x=0.20)$ bulk glasses in the $\mathrm{Ge}_{x} \mathrm{Te}_{1-x}$ system, (b) vitreous droplets of g-GeTe $\mathrm{Ger}_{2}$ after a splat quenching onto a liquid nitrogen cooled metallic plate, (c) compositional dependence of $T_{\mathrm{g}}$ in the Ge-Te system. The DSC signal of g-GeTe was multiplied by a factor of 10 , and the traces were shifted vertically for better visibility. The $T_{\mathrm{g}}$ values for glasses synthesized in our laboratory are shown by the red squares. The gray symbols (circles, squares, triangles, diamonds, etc.) correspond to bulk glasses and thin films $\mathrm{Ge}_{x} \mathrm{Te}_{1-x}$, reported in Refs. [S1-S8]. The crystallization temperatures $T_{x}$ for amorphous GeTe films are shown by gray stars. The expected $T_{\mathrm{g}}$ value for $\mathrm{g}$-GeTe was assumed to be $10 \mathrm{~K}$ lower compared to $T_{x} \cdot{ }^{\mathrm{Sg}}$ 

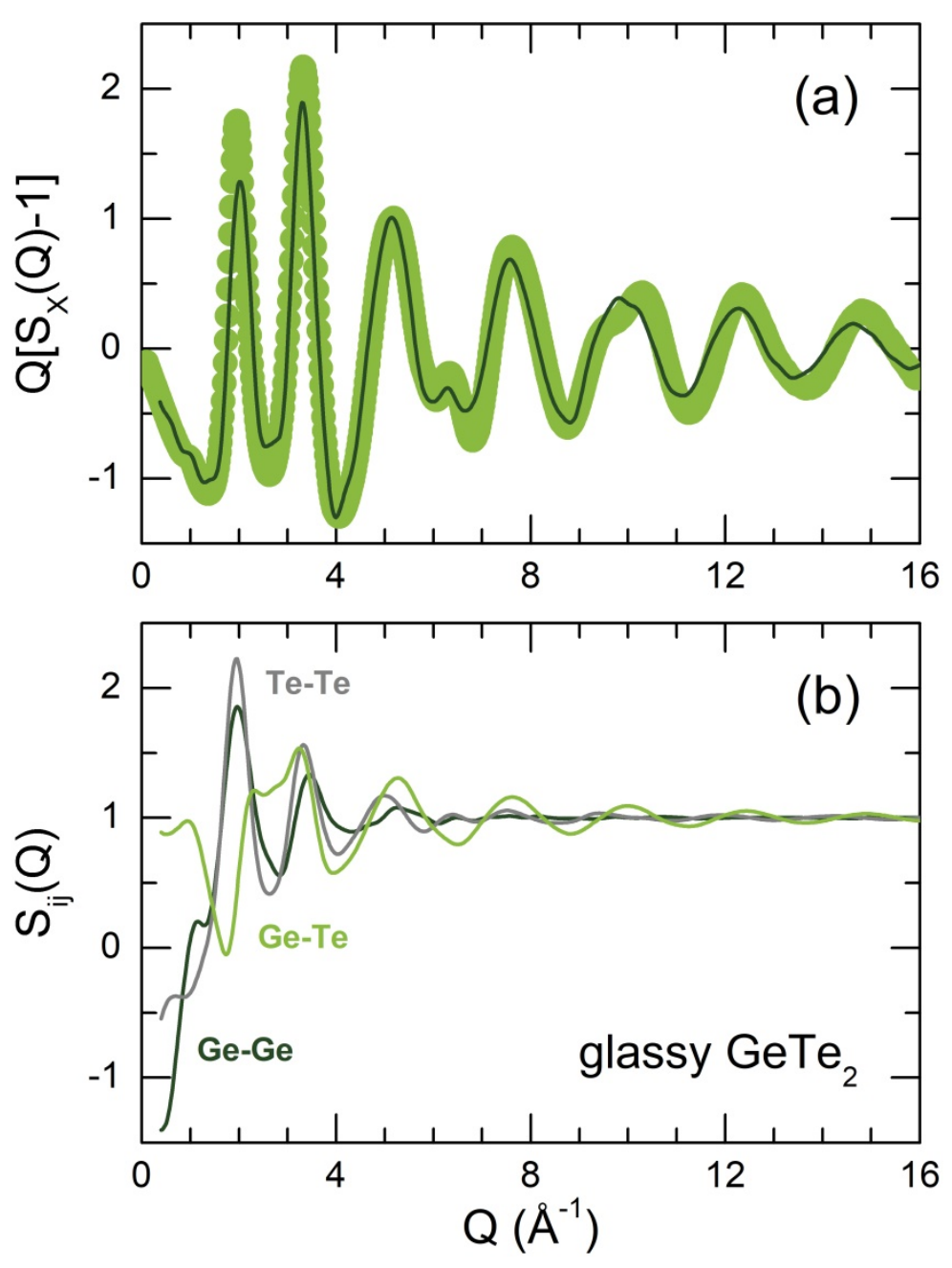

Figure S2. (a) Experimental and derived FPMD interference functions $Q\left[S_{\mathrm{X}}(Q)-1\right]$ for glassy $\mathrm{GeTe}_{2}$; (b) partial structure factors $S_{\mathrm{ij}}(Q)$ for Ge-Ge (dark green), Ge-Te (light green) and Te-Te (gray) atomic pairs. 


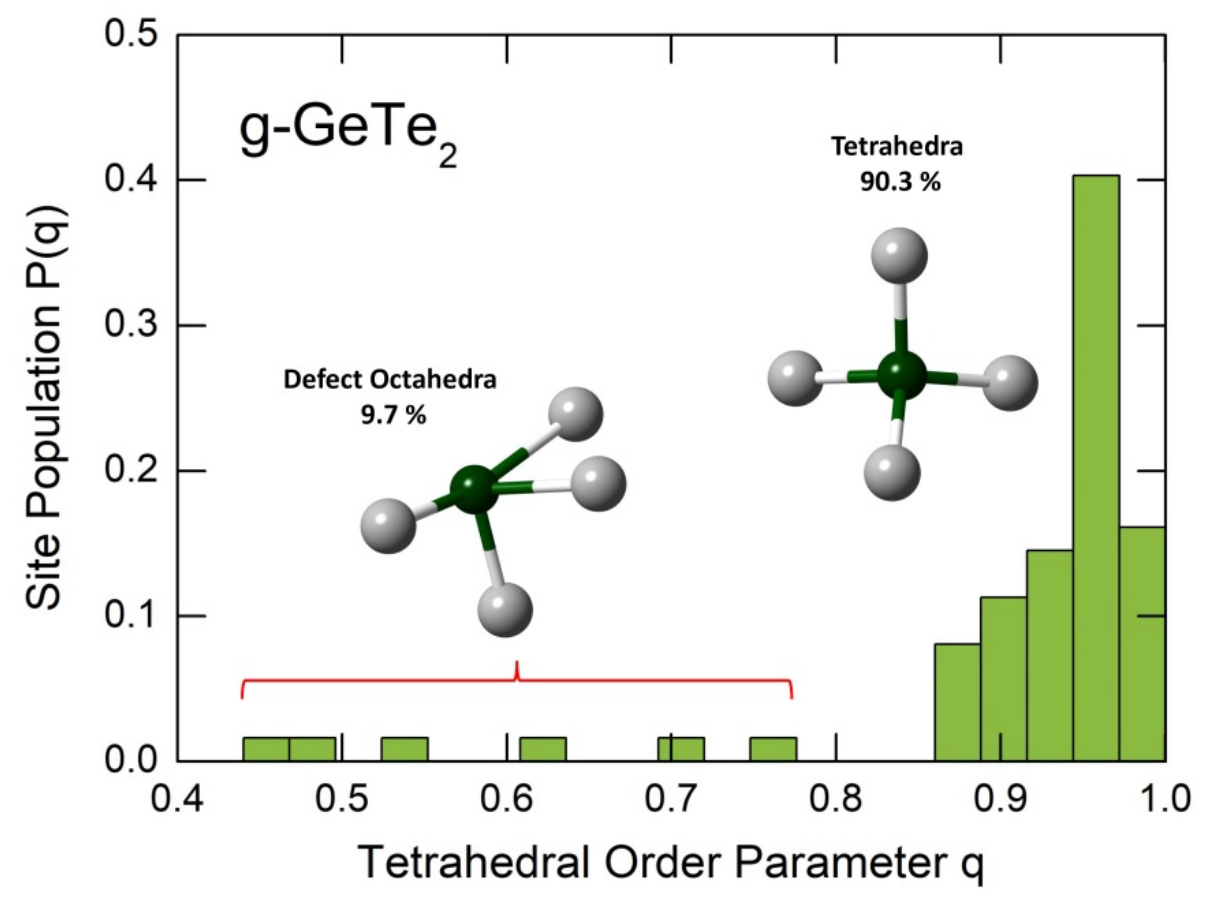

Figure S3. Tetrahedral orientational order parameter $q^{\mathrm{s} 10, \mathrm{~S} 11}$ for $\mathrm{GeTe}_{4}$ polyhedra in bulk glassy $\mathrm{GeTe}_{2}$. 


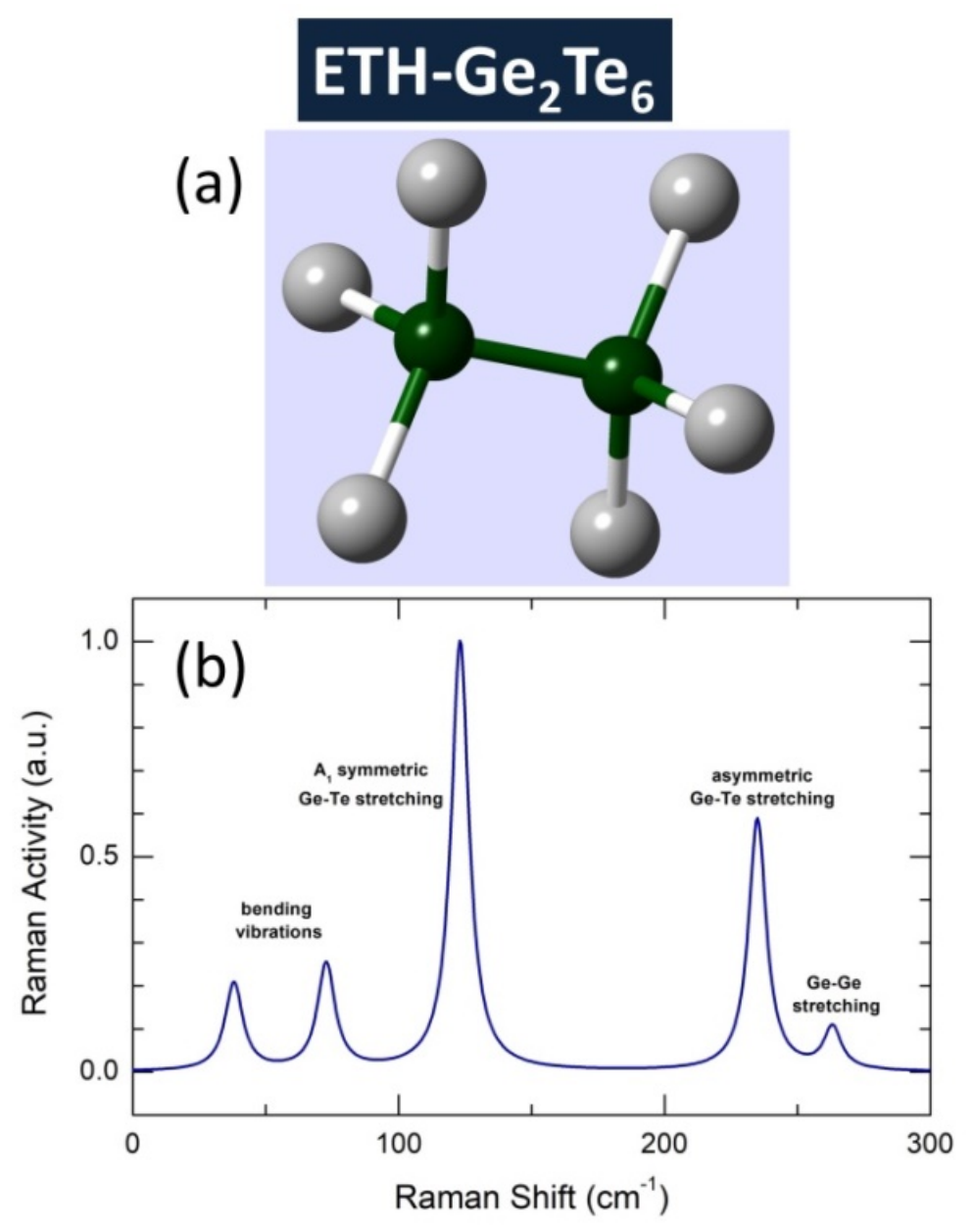

Figure S4. (a) Optimized DFT cluster ETH- $\mathrm{Ge}_{2} \mathrm{Te}_{6}$ and (b) derived DFT Raman spectrum. The terminal hydrogen atoms are not shown, and the H-related vibrations are removed from the spectrum. 

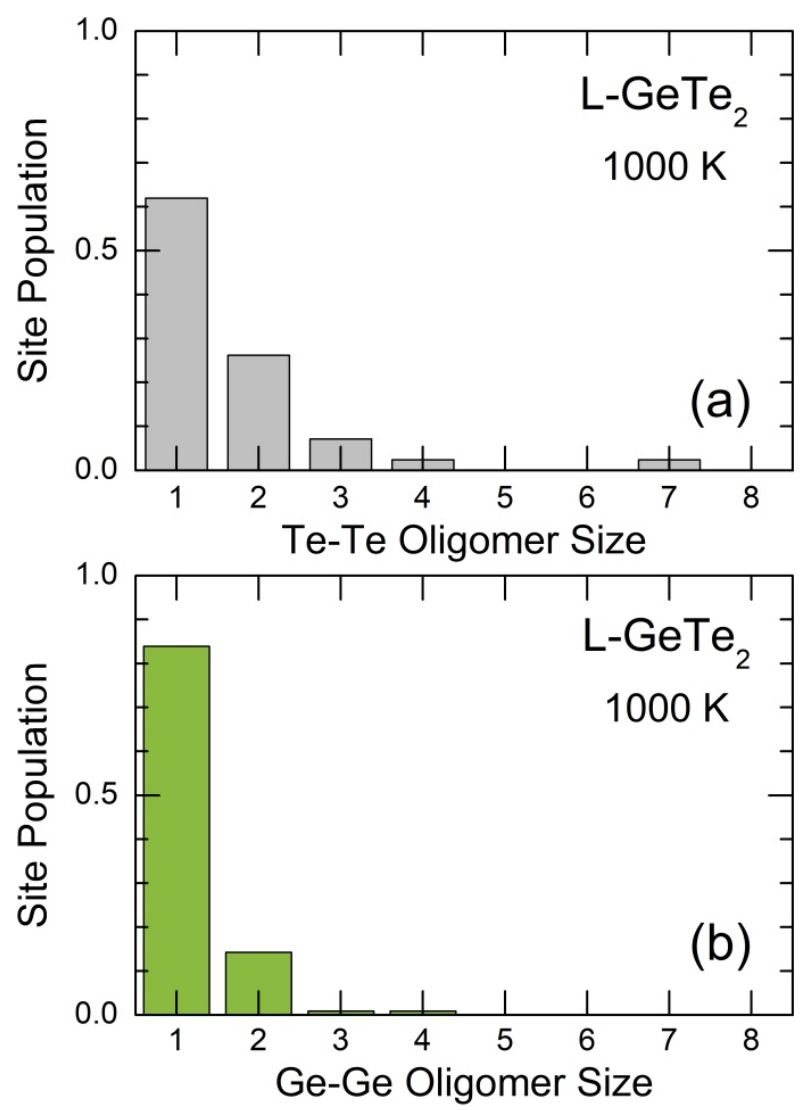

Figure S5. Size of (a) $\mathrm{Te}_{n}$ and (b) $\mathrm{Ge}_{n}$ oligomers in liquid $\mathrm{GeTe}_{2}$ at $1000 \mathrm{~K}$. 


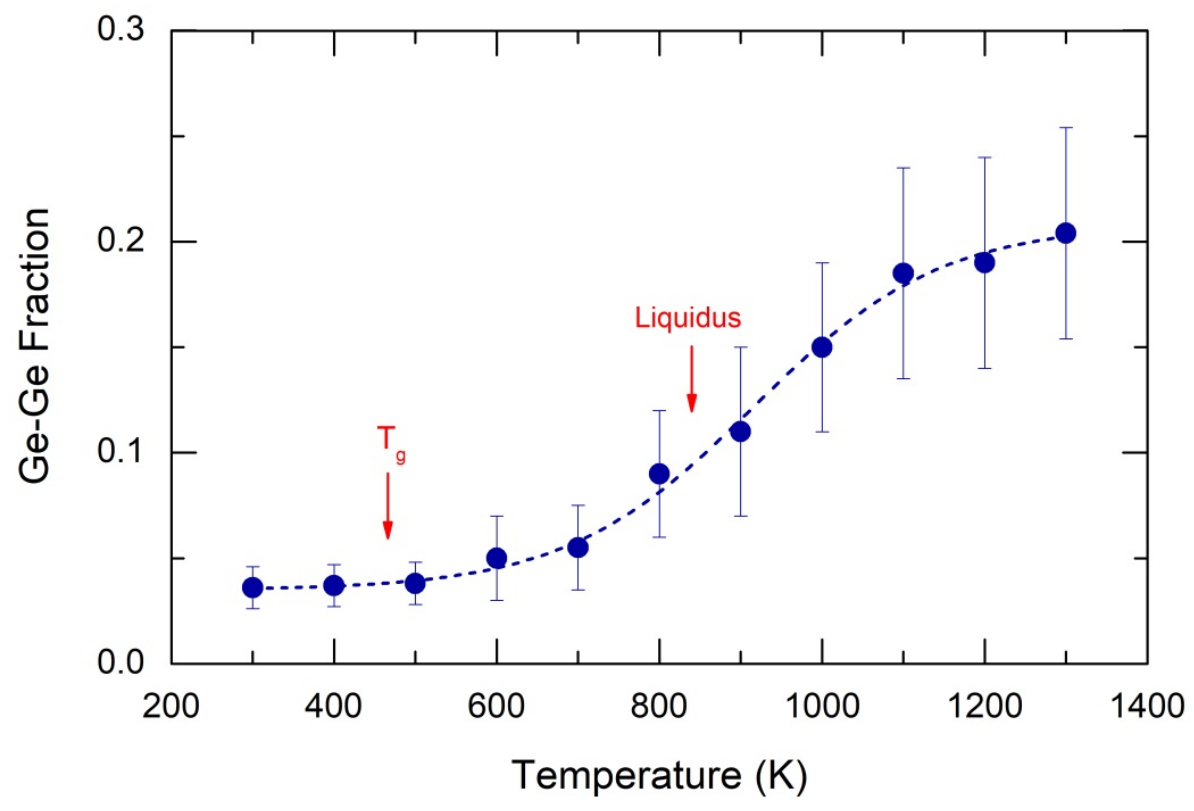

Figure S6. Fraction of Ge-Ge homopolar bonds in glassy, supercooled and liquid $\mathrm{GeTe}_{2}$ as a function of temperature. 


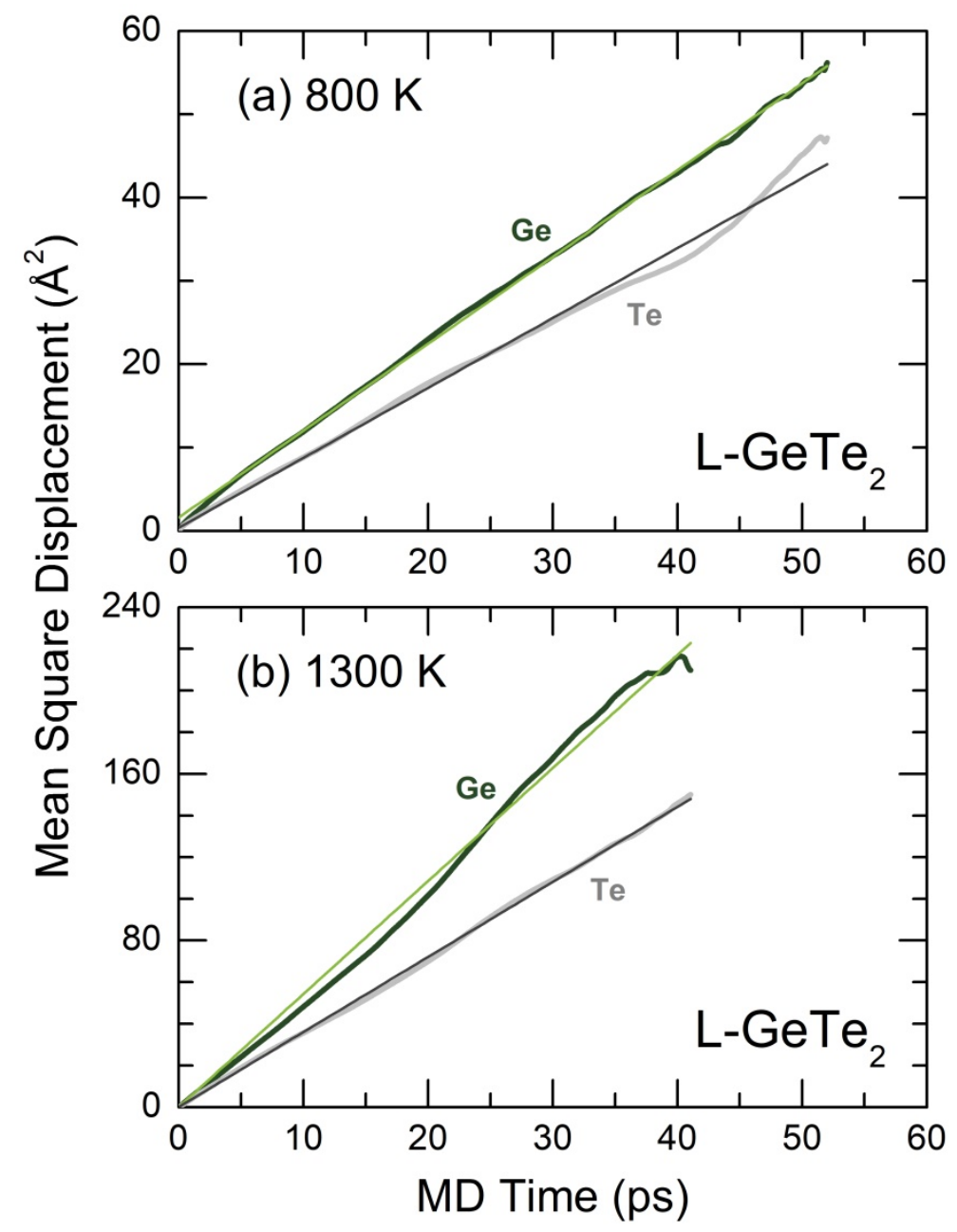

Figure S7. Germanium and tellurium mean-square displacements in liquid $\mathrm{GeTe}_{2}$ at (a) $800 \mathrm{~K}$ and (b) $1300 \mathrm{~K}$. The thin solid lines represent the results of linear least-square fits of the experimental data points. 


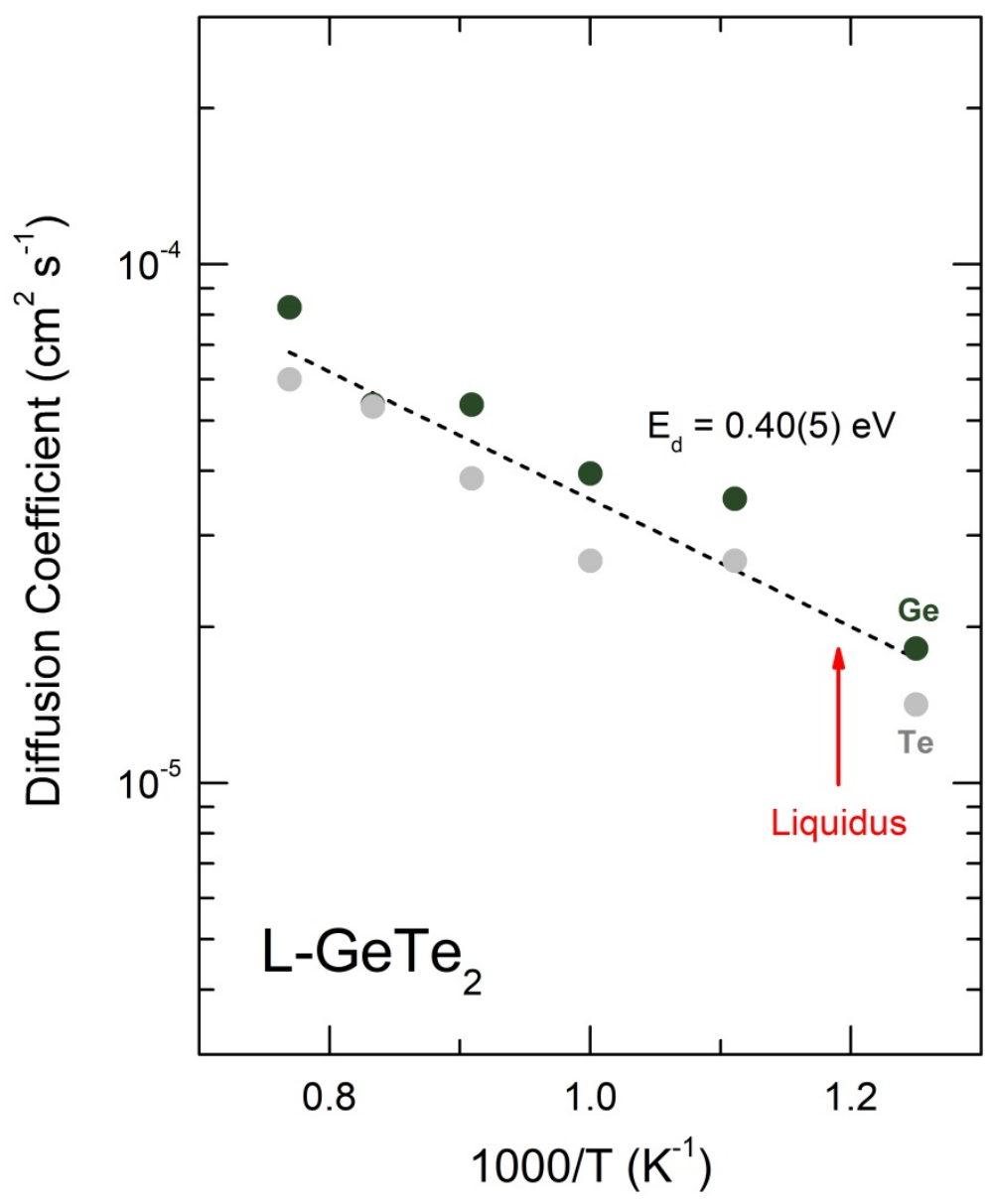

Figure S8. Germanium $D_{\mathrm{Ge}}$ (dark green) and tellurium $D_{\mathrm{Te}}$ (light gray) diffusion coefficients in liquid $\mathrm{GeTe}_{2} ; D_{\mathrm{Ge}}(T) / D_{\mathrm{Te}}(T)=1.31 \pm 0.16$; the apparent diffusion activation energy using an Arrhenius-type equation $D=D_{0} \exp \left(-E_{\mathrm{d}} / k T\right)$ is $E_{\mathrm{d}}=0.40 \pm 0.05 \mathrm{eV}$. 
Table S1. Optimized Geometry Parameters (Ge-Te, Ge-Ge and Te-Te interatomic distances, Te-GeTe and Ge-Te-Ge bond angles) of Size-Limited Ge-Te ${ }^{a}$ Clusters Used in DFT Modeling of Vibrational Properties

\begin{tabular}{|c|c|c|c|c|c|}
\hline & $\begin{array}{c}\text { Ge-Te } \\
(\AA)\end{array}$ & $\begin{array}{c}\text { Ge-Ge } \\
(\AA)\end{array}$ & $\begin{array}{c}\text { Te-Te } \\
(\AA)\end{array}$ & $\begin{array}{c}\text { Te-Ge-Te } \\
\text { (deg) }\end{array}$ & $\begin{array}{c}\text { Ge-Te-Ge } \\
\text { (deg) }\end{array}$ \\
\hline \multicolumn{6}{|c|}{ 4-fold coordinated Ge } \\
\hline $\mathrm{CS}-\mathrm{Ge}_{2} \mathrm{Te}_{7}^{a}$ & $2.616(5)$ & $4.134^{b}$ & - & $109(6)$ & 104.1 \\
\hline ES- $\mathrm{Ge}_{2} \mathrm{Te}_{6}{ }^{a}$ & $2.617(10)$ & $3.435^{b}$ & - & $109(7)$ & 81.7 \\
\hline $\mathrm{ETH}-\mathrm{Ge}_{2} \mathrm{Te}_{6}{ }^{a}$ & 2.623 & 2.486 & - & $109(3)^{c}$ & 104.1 \\
\hline $\mathrm{GeTe}_{8}^{\mathrm{a}}$ & $2.640(1)$ & - & 2.780 & $109(4)$ & - \\
\hline $\mathrm{GeTe}_{12}{ }^{\mathrm{a}}$ & $2.636(15)$ & - & $2.775(4)$ & $109(4)$ & - \\
\hline \multicolumn{6}{|c|}{ 3-fold coordinated Ge } \\
\hline $\mathrm{CS}-\mathrm{Ge}_{2} \mathrm{Te}_{5}{ }^{a}$ & $2.658(21)$ & $4.560^{b}$ & - & $111(12)$ & 111.8 \\
\hline $\mathrm{ES}-\mathrm{Ge}_{2} \mathrm{Te}_{4}{ }^{a, d}$ & $2.638(40)$ & $3.236^{b}$ & - & $108(10)$ & 75.3 \\
\hline $\mathrm{ES}-\mathrm{Ge}_{2} \mathrm{Te}_{4}{ }^{a, e}$ & $2.664(21)$ & $3.406^{b}$ & - & $108(15)$ & 78.1 \\
\hline $\mathrm{GeTe}_{6}{ }^{\mathrm{a}}$ & $2.653(30)$ & - & 2.780 & $109(9)$ & - \\
\hline $\mathrm{GeTe}_{9}^{\mathrm{a}}$ & $2.660(15)$ & - & $2.833(30)$ & $110(3)$ & - \\
\hline
\end{tabular}

${ }^{a}$ the terminal hydrogen species in the formula are omitted; ${ }^{b}$ the second-neighbor distance; ${ }^{c}$ the average tetrahedral angle including Te-Ge-Te and Te-Ge-Ge bond angles; ${ }^{d}$ the boat conformation; ${ }^{e}$ the chair conformation 


\section{References}

S1 Takamori, T.; Roy, R.; McCarthy, G. J. Structure of Memory-Switching Glasses. I. Crystallization Temperature and its Control in Ge-Te Glasses. Mater. Res. Bull. 1970, 5, 529-540.

S2 DeNeufville, J. P. Chemical Aspects of Glass Formation in Telluride Systems. J. Non-Cryst. Solids 1972, 8-10, 85-105.

S3 Savage, J. A. Glass Formation and DSC data in the Ge-Te and As-Te Memory Glasses. J. Non-Cryst. Solids 1972, 11, 121-130.

S4 Sarrach, D. J.; DeNeufville, J. P.; Haworth, W. L. Studies of Amorphous Ge-Se-Te Alloys. I. Preparation and Calorimetric Observations. J. Non-Cryst. Solids 1976, 22, 245-267.

S5 Saiter, J. M.; Chebli, K.; Hamou, A. Enthalpy Relaxation and Structure in Vitreous $\mathrm{Ge}_{15} \mathrm{Te}_{85}$. Physica B 2000, 293, 98-107.

S6 Bletskan, D. I. Glass-Formation and Crystallization in the System Ge-Te. Chalcogenide Lett. 2005, 2,121-124.

S7 Petkov, P.; Ilcheva, V.; Petkova, T.; Ilchev, P. Thermal Studies of Ge-Te-Ga Glasses. AIP Conf. Proceedings 2010, 1203, 932-936.

S8 Jóvári, P.; Piarristeguy, A.; Escalier, R.; Kaban, I.; Bednarčik, J.; Pradel, A. Short range order and stability of amorphous $\mathrm{Ge}_{x} \mathrm{Te}_{100-x}$ alloys $(12 \leq x \leq 44.6)$. J. Phys.: Condens. Matter 2013, 25 , 195401.

S9 Kalb, J. A.; Wuttig, M.; Spaepen, F. Calorimetric Measurements of Structural Relaxation and Glass Transition Temperatures in Sputtered Films of Amorphous Te Alloys Used for Phase Change Recording. J. Mater. Res. 2007, 22, 748-754.

S10 Chau, P.-L.; Hardwick, A. J. A New Order Parameter for Tetrahedral Configurations. Mol. Phys. 1998, 93, 511-518.

S11 Errington, J. R.; Debenedetti, P. G. Relationship between Structural Order and the Anomalies of Liquid Water. Nature 2001, 409, 318-321. 